\title{
Cognitive Explanation of "Away" within the Framework of Semantic Schema
}

\author{
Lixia Liao \\ Qiannan Normal College for Nationalities, Duyun, China \\ Email:918329268@qq.com
}

How to cite this paper: Liao, L.X. (2017) Cognitive Explanation of "Away" within the Framework of Semantic Schema. Open Journal of Social Sciences, 5, 248-257. https://doi.org/10.4236/jss.2017.58020

Received: August 1, 2017

Accepted: August 27, 2017

Published: August 30, 2017

Copyright $\odot 2017$ by author and Scientific Research Publishing Inc. This work is licensed under the Creative Commons Attribution International License (CC BY 4.0).

http://creativecommons.org/licenses/by/4.0/

\begin{abstract}
Particles play a very vital role in the language of English. Particles are mostly used as elements that help to encode grammatical categories. And it is one of the compulsory testing items in different kinds of examinations, such as TEM-4, TEM-8, CET-4 and CET-6. It is noted that particles have been distressing the students and teachers in China, which has been confirmed by the multiple testing outcome. Traditional schools of linguists hold the view that the complex senses of particles and their complicated collocations are idiomatic and arbitrary. Cognitive linguists believe that there exist certain logical relationships among the multiple senses of particles. Based on the theory of image schema, this paper discusses the projection of the particle "away" from the basic spatial domain to other non-spatial or abstract domains, thus analyzing the multiple meanings of "away" from a new perspective.
\end{abstract}

\section{Keywords}

Away, Semantic Schema, Cognitive Projection, Semantic Extension

\section{Introduction}

Within the framework of the image schema theory of cognitive linguistics, this paper analyzes the central image schema of the particle "away" and points out that the central image schema can be static as well as dynamic. It argues that by means of the conceptual metaphor mechanism, the basic schema can be extended to a few abstract domains such as domain of time, domain of disappearance, domain of absence, domain of storage, forming a network system of different semantic meanings of "away". The spatial and non-spatial meanings of "away" can help us understand this word better. The cognitive expressions of "away" can reveal the human being process of general cognitive domain, which is helpful for constructing the dimensions of time and space. 


\section{Literature Review}

\subsection{Cognitive Studies on Particles}

\subsubsection{Lindner's Study}

Cognitive linguistics has been established against the assertions and principles of Generative Linguistics, and is divided into two branches, which are called cognitive grammar and cognitive semantics. Langacker's cognitive grammar attracted many followers [1]. Susan Jean Lindner's (1982) doctoral dissertation was written from the perspective of Ronald Langacker's space grammar, investigated the semantic structure of Verb Particle Constructions (VPC abbreviated), and especially analyzed particles like out and up [2]. According to cognitive grammar, particles are not arbitrarily structured; there is a continuum between syntactic and lexical structure based on degrees of analyzability, productivity and regularity. So the lexical units like out and up should have many concrete and abstract meanings. The dissertation established diverse semantic patterns by analyzing 600 VPC with out and 1200 VPC with up. Lindner pointed out that the prototypical meaning of out as the removal or departure of one concrete object from within another object or place, then presented some variations both in specification of the Landmark and the Path profile. At last, she listed some semantic extensions of out in non-spatial domains according to corpus study.

\subsubsection{Brugman's Study}

Hill (1982) made a contrastive study of up/down, front/back and left/right in Hausa and English [3]. Vanparys (1984) regarded some particles such as from, off and out as the source domain in metaphor analyses [4]. Different from Linder's experiential view, Brugman (1981) is famous for her pioneering work in analyzing English particle over from the view of prominence [5]. She examined the spatial relationships from the figure/ground segregation.

\subsubsection{Langacker's Study}

As a pioneer in cognitive linguistics, Langacker (1987) adopted three terms Trajector (TR), Landmark (LM) and Path to describe the internal construction of image schema: the object located is termed as the Trajector and the object which serves as a reference point is the Landmark [6]. Thus spatial location of TR is determined with LM as its reference. And the course that TR has undergone is named as Path. The term of Path is widely applied to analyze spatial words. However, different from Langacker's study, Taylor (2002) focus on other aspects: such as the static and dynamic relationship between Landmark and Trajector, the distance between Trajector and Landmark, and the direction of Trajector relative to Landmark etc [7].

\subsubsection{Tyler and Evans' Study}

Different from other foreign linguistics, Tyler and Evan (2003) not only studied the particle over from the perspective of cognitive linguistics, but also applied it in classroom teaching [8]. They considered that the traditional analyses of par- 
ticles couldn't explain the systematic relations between their multiple uses, proposing a model to analyze the particle on the case of over, the main idea of which is that any particle can form a polysemous network around a central sense based on bodily-experience. The analysis model of over includes two parts: the central sense and the extending meanings beyond the proto-sense, which can give some implications to research other particles such as "away". The valuable part of their research on particle over is the combination with instruction, which is especially beneficial for the second language learners of English.

\subsection{The Application of Image Schema Theory in Particles Research Abroad}

Image schema theory has become an active sub-branch within the cognitive approach in the past decades. Nagy (1974) found out that there were some links between literal vertical position and change of value on non-spatial scales such as moral value [9]. Some metaphorical expressions include three typical source particles: from, off, out. More cognitive linguists analyzed particles within the framework of Cognitive Linguistics, who claimed that the distinct senses of a particular particle were related and formed a radial network with a central sense and other extended meanings [10] [11] [12]. The links between the central member and the peripheral members are defined by the transformation of image schema and metaphorical mappings.

\subsection{The Application of Image Schema Theory in Particles at Home}

Compared with the various researches on image schema theory abroad, the corresponding analyses at home are comparatively not that heated. Most linguists mainly brought in the theories in past two decades, of which the basic definition, function, and development of image schema theory were introduced to Chinese scholars in order to attract more attention: introducing the Cognitive Grammar; Cognitive Linguistics; Cognitive Semantics. Some scholars took efforts to introduce the latest development of the image schema studies abroad and discussed the researching potential of image schema theory both at home and abroad, mentioning that "too much theoretical work has been done and the researches remain to be strengthened in applications at home." However, the semantic development of particles and the applications in classroom teaching within the framework of image schema theory were hotly discussed by scholars. For example, some researchers discussed the semantic development of particles and regarded image schema theory as a powerful tool in explaining the semantic extension of particles, analyzed the cognition of in with image schema theory, checked the metaphoric extension of it and drew a table to indicate the frequency of its usages; Some studied the frequency of usages and the misuse of particles systematically; Some made the research on how to do the teaching from the perspective of cognitive linguistics; Others also discussed the metaphorical extensions of the particle and did a research on particles teaching, taking the particle over as the example from the perspective of image schema theory. 
The researches above have their own advantages in analyzing the semantic extensions of particles: The foreign researchers mainly focused on theoretical aspects, while the Chinese scholars paid more attention to classroom teaching. However, they seldom studied the particles based on spoken English especially from our daily life. The various complex senses of particles are usually listed at random in the items of a dictionary, which is difficult for readers to understand as a whole. From the perspective of cognitive linguistics, the various meanings of a word are not arbitrary, but relevant to each other. Meanwhile, the metaphorical extensions of particles are based on experientialism, image schema and the metaphorical mappings from spatial domains to abstract domains. However, the semantic extensions of away will leave great exploring space and will be analyzed systematically.

\section{Theoretical Foundations}

\subsection{Image Schema Theory}

This paper takes image schema theory as its framework, which can account for away's spatial senses. Meanwhile, their metaphorical extensions are elaborated by metaphorical mappings.

\subsubsection{The Definition of Image Schema}

An image schema is a recurring structure within our cognitive process which establishes patterns of understanding and reasoning. The image schema refers to "relatively simple structures that constantly recur in our everyday bodily experience: CONTAINER, PATHS, LINKS, FORCES, BALANCE, and in various orientations and relations: UP-DOWN, FRONT-BACK, PART-WHOLE, CENTERPERIPHERY etc [13]." Holmqvist gave a rather detailed description of image schema [14]: "It could be said to be that part of a picture which remains when the whole structure is removed from the picture, except for that which belongs to a single morpheme, a sentence or a piece of text in a linguistic specified description of a picture... that which remains is a highly fluid image, in some aspects... but completely unspecified in others...". Briefly, an image schema is considered a description of perceptual experience for the purpose of mapping spatial structures onto conceptual structures. As a composite notion, image schema is neither fixed nor specific, even as they manifest characteristics of each. Many image schemas have "topological" characteristics, insofar as they constitute "spaces" sectioned into areas without specifying actual magnitude, shape, or material. Lakoff's definition presented a better explanation about the essence of the term, and his classification provided a scientifically objective way to research image schema. Among all of these image schemas classified by Lakoff, the path schema is closely related to our semantic analysis of away, which is also the most typical image schema based on human bodily experience.

\subsubsection{The Internal Structure of Image Schema}

The internal structure of a typical image schema was explored by Langacker, 
who claimed that image schema was composed of Trajector, Landmark and Path. The object which is located is called the Trajector (TR) and the object which serves as a reference point is named as the Landmark (LM). Thus spatial location of TR is positioned with LM as its reference. And the course that TR has undergone is named as Path. Of course, there is still an observer besides Trajector, Landmark and Path, who can make a distinction of the static or dynamic special relationships between Trajector and Landmark. Lindner (1982) applied the internal structure of image schema to study the verb particle construction with out, in which she summarized different versions of image schema about out [2].

\subsection{Cognitive Metaphor Theory}

Metaphor, as a very important way to gain abstract meanings, is conceptual and systematic in nature. It is made up of two domains by metaphorical mapping which is grounded in our bodily experience, a relatively more clearly structured source domain and a relatively more abstract structured target domain. If the source domain is the domain of space, then it maps the image-schematic structure of the space domain onto that of non-spatial \& abstract domains, thus enabling us to talk about and think something of non-spatial in spatial concepts. This mapping procedure always takes place unconsciously and automatically, and in this way can some words get multiple meanings.

Two hypotheses proposed by Lakoff (1987: 69) go like these [13]: 1) Basiclevel categories and image schema are the two kinds of pre-conceptual structure directly meaningful to us; 2) One way in which the abstract concepts arise from these two kinds of pre-conceptual structure is by metaphorical mapping. We can automatically acquire some sorts of cognitive pattern or schema such as up, down, out, and so on. The image schema is very important in our abstract thinking, the functions of which Lakoff $(1987,275)$ highlighted as "image schema provides particularly important evidence for the claim that abstract reasoning is a matter of two sides [13]: 1) reason based on bodily experience; and 2) metaphorical mappings from concrete to abstract domains". It is found that image schema not only constructs our experience of space but also constructs concepts in abstract domains.

\section{Analyses of Cognitive Schema and Semantic Extension of the Particle "Away"}

\subsection{The Central Image Schema}

A word has both central senses and metaphorical senses. Central Sense: A word's central sense is defined as: it's the most usual or primary one without metaphors or allegories. Adverbial particles have a central meaning of motion, in which the sense of motion is highlighted. Adverbial particles usually refer to spatio-directional domains, so they should carry spatio-directional motion as their central sense. The first ordering of adverbial particles' central senses in dictionaries indicates that such literal senses are most frequently used by native speakers of 
English. Metaphorical Sense: Just like any other kinds of words in English, few adverbial particles are monosemous. Most adverbial particles have undergone the development of their polysemous senses in the history of English word stock. By means of radical extensions, adverbial particles have obtained many other kinds of senses from their central ones. One of the extending devices of word sense is metaphorical mapping. Cognitive linguists hold "that metaphor is a thinking device and we human beings, consciously or unconsciously, use metaphors to think and communicate in daily routines [12]".

\subsection{Spatial Domain of "Away"}

The word away can solely function as an adverbial particle instead of a preposition and its meanings are quite complicated.

\subsection{1. "Away" in the Sense of Path}

Like other adverbial particles, away essentially denotes spatio-directional motion and thus is a path word. It profiles the trajectory along which a trajector moves with a landmark as the reference point. This trajectory consists of a series of consecutive locations. Since away focuses upon motion sense, its destination is very often implicit and the path is rarely highlighted. The trajector is usually animate, while the landmark, which simply coincides with the source in this sense of away, can appear in the subordinate clause or is introduced by the preposition from. Taking (1) and (2) for example.

1) When John saw the dog, he ran away.

2) People in the village had been driven away from their homes by the invading army.

\subsection{2. "Away" in the Sense of Direction}

The above path schema inherently bears the property of direction. When it combines with certain verbs, this directional feature is motivated, with its sense of motion being reduced to a lesser extent. A person often is the trajector and the landmark can be the cause of the trajector's behavior, since this kind of landmark often causes unhappiness or danger upon the trajector. In sentence (3), the person she stands for a small part of her whole body-her eyes. Obviously, the trajcetor is static in relation to the landmark from the conceptualizer's perspective. Actually, (3) can be construed as the trajcetor's (her eyes) traversal from the landmark (John) to the goal. Therefore, the motion sense of away clearly contributes to its sense of direction. The case is also true with sentence (5).

3) John was staring at her. She looked away, feeling suddenly shy and embarrassed.

4) She turned away from the door and walked over to the table.

5) A path leads away from the back of the house.

\subsection{3. "Away" in the Sense of Distance}

When away is preceded by the linguistic units expressing distance, the trajectory 
is always implicit. In (6), the subject itself is the goal of the path schema. In (7), the spot where Mary's brother was standing is also the goal. The source or landmark can either be implicit or explicit. Under this circumstance, the entire length of the trajectory in the path schema comes into prominence. Etymologically, the original sense of away is on one's way whose meaning carries this following element-the distance from the source. To be self-evident, it is activated and mapped onto away's sense of distance.

6) The nearest hotel is about eight miles away.

7) Mary's brother is standing only a few feet away from me.

\subsection{Temporal Domain of "Away"}

A certain kind of event or situation occurs inevitably within a certain scope of space. And its movement or existence through space can help us with our metaphorical understanding of time. If a person travels (in place) from point $A$ to Point $\mathrm{B}$, he or she also traverses (in time) from point $\mathrm{A}$ to point $\mathrm{B}$. The longer a person undergoes a course, the more time it will take. Hence, we have the metaphor TIME IS A PATH in which time is perceived in terms of spatial concepts. And the passage of time is conventionally represented as a one-dimensional line.

Spatial away denotes that a trajector takes up a series of continuous locations in a path. Similarly, temporal away may assign a trajector to a series of consecutive points on the time line. Therefore, in cases such as (8), temporal away denotes that its trajectory is the continuous time line, and its landmark implies the time point when the speech event is just taking place. This temporal usage of away corresponds to its spatial usage exemplified in (6) and (7).

8) The holiday is less than three weeks away.

The original sense of away-onward carries this particular meaning: continuous movement in space and time. Later it is found that activities (such as working, dancing, chattering, and singing) require taking up a series of consecutive points on the time line in order to be finished. As a result, continuous away is mapped metaphorically onto these new domains. In such usage of away, the trajector is animate, while the landmark is always absent.

9) Susan was at her desk working away as usual.

10) The children were all chattering away happily.

Immediate away is a special case of continuous away, for it only occupies a certain point on the time line. The act of leaving a place is instantaneous in time. So it is quite natural for this instantaneous property of away to be invoked and mapped metaphorically onto other cognitive domains, such as asking, firing and so forth. This usage of away primarily occurs in imperative clauses.

11) Right away!

12) Fire away!

13) Ask away!

\subsection{Abstract Domains of "Away"}

Just like temporal relations, abstract senses can also be analyzed on the basis of 
spatial concepts.

\subsection{1. "Away" in the Sense of Disappearance}

The sense of leaving a place involves disappearing from that specified source. And some other new cognitive target domains (the fading of sound, the melting of snow, the dying of music, etc.) also have this particular trait. Therefore, when away is used to describe such phenomena, it naturally acquires this sense of disappearance. Under this circumstance, the trajector is usually assigned to a physical or an abstract entity, such as snow, ice, music, sound and voice. And the landmark rarely comes into the conceptulizer's visual field, since it is of little importance in the communication. The disappearing action is a slow and gradual process until into a complete extinction. Very often the source and the path are all ignored. Sentence (16) is a metaphorical extension in which anger is compared to snow and the melting property is mapped onto the target domain of anger.

14) The sound of their voices faded away into the distance.

15) The music died away. Tom gave all his money away to charity.

16) Martha's anger suddenly melted away.

\subsection{2. "Away" in the Sense of Storage}

As mentioned above, away is chiefly a path word, so it inevitably has an ending point as its destination. When away is used in combination with such lexical items as put, hide, the destination for the moving activity is activated and made prominent. Naturally, this storage sense of away has come into being. In addition, the destination brings new meaning to away: enclosed and safe. The trajectors are usually assigned to physical or abstract entities (toys, money, treasures) while the landmarks are quite implicit, since they are only known to the agents.

17) Put your toys away before you go to bed.

18) He's got lot of gold coins hidden away somewhere.

19) Thousands of archaeological treasures are being kept hidden away.

\subsection{3. "Away" in the Sense of Absence}

Since away is primarily a path word, leaving a certain place means being not in that particular point any more. Therefore, the feature of not being in that particular place can be mapped onto the following activities. Hence, the abstract sense of away-being absent has appeared. In such cases, the trajector is always the person while the landmark can be explicit or implicit. In (20) and (21), the prepositions following away express the reason of being absent.

20) He is away with flu.

21) Kate is away on holiday.

22) Mary is away from school today!

\subsection{An Overview of the Meanings of "Away"}

According to Rudzka and Ostyn (2003: 139), "away is the seventh most frequently used adverb among all the adverbial particles and prepositions. Origi- 
nally, it means on one's way, and then it extends to the following meaning: from this (or that) place [11]." Gradually, its original meaning becomes obsolete and thus is not included in modern English dictionaries. Nowadays, it has three most important senses: 1) leaving a place or not being at it;2) continuously; without stopping; and 3) complete disappearance [15]. The basic spatial sense of away can be extended to abstract domains like temporal sense, sense of disappearance, sense of absence and sense of storage through metaphorical mappings.

\section{Conclusion}

This paper implemented a cognitive semantic analysis of the spatial and metaphorical senses of the adverbial particle away. It reveals that the latter ones have evolved from the former one, which is in line with human cognitive processes. Through the analysis of the senses of adverbial particle away, foreign learners of English can have a vivid picture of their meaning extending processes and gain profound insights into their metaphorical senses. Logical arrangements of items in terms of mapping from spatial domains to abstract domains in Learners' Dictionaries plus cognitive explaining will make it easier to facilitate the mastery of particles. Therefore, it is important to develop the metaphoric competence of second language learners since it can contribute to language abilities and skills. This research is important to develop the metaphoric competence of second language learners since it can contribute to language abilities and skills.

\section{References}

[1] Langacker, R.W. (1991) Foundations of Cognitive Grammar Vol. II: Descriptive Application. Stanford University Press, California.

[2] Lindner, S.J. (1982) A Lexico-Semantic English Verb Particle Constructions with out and up. University of California, Oakland.

[3] Hill, C.A. (1982) Up/Down, Front/Back, Left/Right: A Contrastive Study of Hausa and English. In: Weissenbord. J. and Klein, W., Eds., Here and There: Cross-Linguistic Studies on Deixis and Demonstration, John Benjamins, Amsterdam, 13-42.

[4] Vanparys, C. (1984) Methodology and Analyses of the Preposition in. Cognitive Linguistics, 5, 157-184.

[5] Brugman, C. (1981) Story of OVER. University of California, Berkely.

[6] Langacker, R.W. (1987) Foundations of Cognitive Grammar. Theoretical Prerequisites. Stanford University Press, Stanford.

[7] Taylor, J.R. (2002) Cognitive Grammar. Oxford University Press, Oxford.

[8] Tyler, A. and Evans, V. (2003) The Semantics of English Particles. Cambridge University Press, Cambridge.

[9] Nagy, W.E. (1974) Figurative Patterns and Redundancy in the Lexicon. University of California, San Diego.

[10] Dewell, R.B. (1994) Over Again: Image-Schema Transformations in Semantic Analysis. Cognitive Linguistics, 5, 351-380. https://doi.org/10.1515/cogl.1994.5.4.351

[11] Evans, V. (2001) Reconsidering Prepositional Polysemy Networks: The Case of Over. Language, 77, 724-766. https://doi.org/10.1353/lan.2001.0250

[12] Lakoff, G. and Johnson, M. (1980) Metaphors We Live By. The University of Chi- 
cago Press, Chicago.

[13] Lakoff, G. (1987) Women, Fire, and Dangerous Things: What Categories Reveal about the Mind. The University of Chicago Press, Chicago. https://doi.org/10.7208/chicago/9780226471013.001.0001

[14] Holmqvist, K. (1993) Implementing Cognitive Semantics. Lund University Cognitive Studies, Lund.

[15] Rudzka, B. and Ostyn, P., Eds. (2003) Word Power: Phrasal Verbs and Compounds. Mouton de Gruyter, Berlin \& New York.

Submit or recommend next manuscript to SCIRP and we will provide best service for you:

Accepting pre-submission inquiries through Email, Facebook, LinkedIn, Twitter, etc. A wide selection of journals (inclusive of 9 subjects, more than 200 journals)

Providing 24-hour high-quality service

User-friendly online submission system

Fair and swift peer-review system

Efficient typesetting and proofreading procedure

Display of the result of downloads and visits, as well as the number of cited articles

Maximum dissemination of your research work

Submit your manuscript at: http://papersubmission.scirp.org/

Or contact jss@scirp.org 